
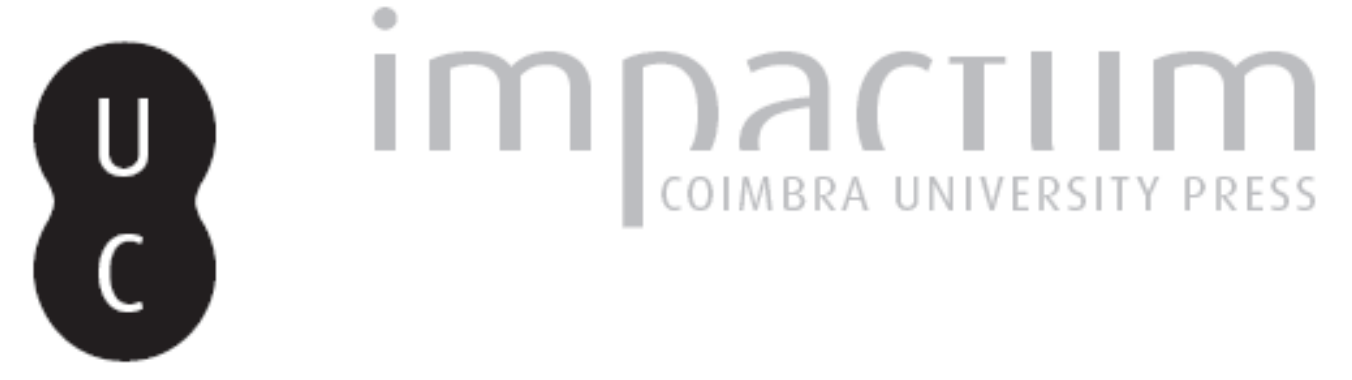

\title{
[Recensão a] Emília Nóvoa Faria e António Martins, A Paixão das Origens. Fotobiografia de Alberto Sampaio
}

\author{
Autor(es): $\quad$ Mendes, José Amado
}

Publicado por: Imprensa da Universidade de Coimbra

URL persistente:

URI:http://hdl.handle.net/10316.2/35452

DOI:

DOI:http://dx.doi.org/10.14195/0870-4147_45_28

Accessed : $\quad$ 26-Apr-2023 10:15:36

A navegação consulta e descarregamento dos títulos inseridos nas Bibliotecas Digitais UC Digitalis, UC Pombalina e UC Impactum, pressupõem a aceitação plena e sem reservas dos Termos e Condições de Uso destas Bibliotecas Digitais, disponíveis em https://digitalis.uc.pt/pt-pt/termos.

Conforme exposto nos referidos Termos e Condições de Uso, o descarregamento de títulos de acesso restrito requer uma licença válida de autorização devendo o utilizador aceder ao(s) documento(s) a partir de um endereço de IP da instituição detentora da supramencionada licença.

Ao utilizador é apenas permitido o descarregamento para uso pessoal, pelo que o emprego do(s) título(s) descarregado(s) para outro fim, designadamente comercial, carece de autorização do respetivo autor ou editor da obra.

Na medida em que todas as obras da UC Digitalis se encontram protegidas pelo Código do Direito de Autor e Direitos Conexos e demais legislação aplicável, toda a cópia, parcial ou total, deste documento, nos casos em que é legalmente admitida, deverá conter ou fazer-se acompanhar por este aviso.

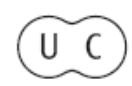




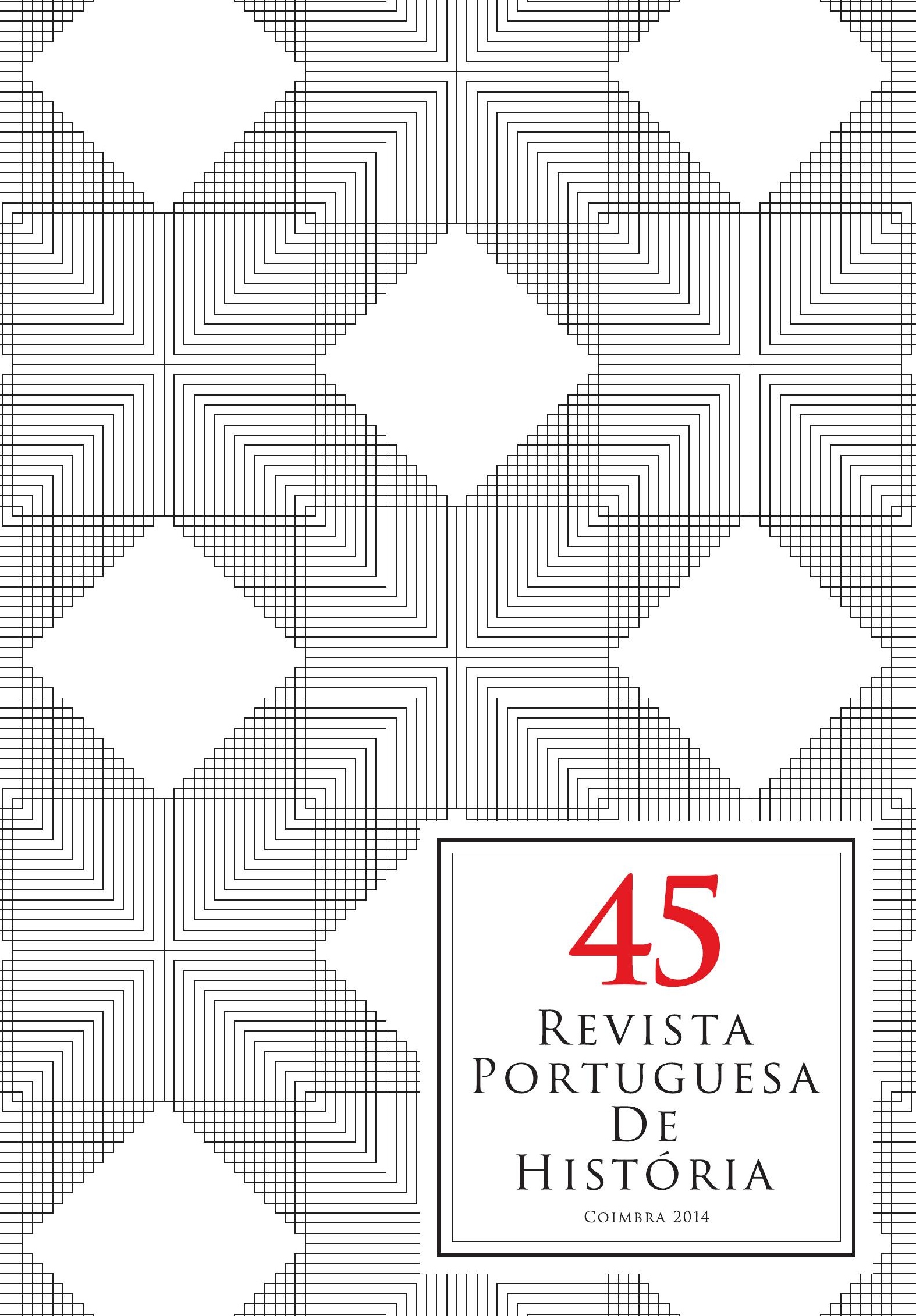


ter a análise, fazendo uma história das políticas emigratórias do Estado Novo a partir das estratégias daqueles que emigraram.

\section{Marina Simões Galvanese}

\section{Emília Nóvoa Faria e António Martins, A Paixão das Origens. Fotobio- grafia de Alberto Sampaio. Prefácio de Guilherme d'Oliveira Martins, Guimarães, Guimarães 2012. Capital Europeia da Cultura, 2012, 417 páginas, ilustrado.}

Alberto da Cunha Sampaio (1841-1908) nasceu em Guimarães, no dia 15 de Novembro de 1841 e faleceu na sua casa de Boamense (freguesia de S. Cristóvão de Cabeçudos, concelho de Vila Nova de Famalicão), em 1 de Dezembro de 1908, com 67 anos de idade. Tratou-se de uma eminente figura da famosa Geração de 70, condiscípulo e amigo de outras notáveis personalidades da segunda metade de Oitocentos e dos inícios de Novecentos, com destaque para Antero de Quental, Oliveira Martins e Eça de Queirós, entre várias outras.

Foi um homem de cultura, um intelectual de elevada craveira, um observador atento e crítico da realidade da sua região e do país, bem como um "verdadeiro historiador de raça". Com efeito, o seu amigo Luís de Magalhães, ao constatar que estávamos perante um autor quase desconhecido do grande público (isto em 1923), acrescentava: «mal suppondo que teem diante de si a obra d'um dos mais auctorisados, laboriosos e meticulosos pesquizadores das nossas origens, d'um verdadeiro historiador de raça, que concentrou o seu trabalho n'um dominio proprio e, n'elle, concorreu para iluminar, d'uma forma verdadeiramente reveladora, períodos históricos até então envoltos em penumbras vagas, quando não em densa obscuridade» ${ }^{1}$.

No domínio da historiografia o seu contributo foi notável, como tem sido frequentemente sublinhado. De facto, Alberto Sampaio desempenhou um papel fundamental no estudo das nossas origens, acrescentando treze séculos à História de Herculano, foi o fundador da história económica de Portugal, intuiu e antecipou-se a Max Weber, acerca da sua conhecida tese sobre a ética protestante e o espírito do capitalismo ${ }^{2}$, valorizou e completou os seus estu-

\footnotetext{
${ }^{1}$ Luiz de Magalhães, «Alberto Sampaio e a sua obra», Aberto Sampaio, Estudos Históricos e Económicos, vol. I, Porto, Livraria Chardron, 1923, p. V.

${ }^{2}$ José Amado Mendes, «Alberto Sampaio e a História Económica», Actas do Congresso Histórico. 150 Anos do Nascimento de Alberto Sampaio, Guimarães, Câmara Municipal de Gui-
} 
dos, recorrendo à exploração de fontes arqueológicas, que iam sendo descobertas pelo seu amigo Francisco Martins Sarmento. Mas o autor das Villas do Norte de Portugal não se interessou apenas pelo nosso passado remoto, pois focou igualmente a história mais recente e, inclusive, a do seu tempo, pelo que o podemos considerar ainda um precursor da chamada "história do presente"”.

Não obstante o sumariamente referido acerca do papel excepcional de Alberto Sampaio para o desenvolvimento dos estudos históricos em Portugal, o autor e a sua obra ainda não atingiram o grau de divulgação que merecem, ao invés do verificado com outras personalidades do seu tempo como, por exemplo, Antero de Quental, Oliveira Martins ou Teófilo Braga. No entanto, também se deve reconhecer que, no último século, foram tomadas iniciativas importantes para promover o estudo e a divulgação da obra do historiador, por excelência, da região de ente o Minho e o Douro. Recordemos as principais.

Em 1923, quando Luís de Magalhães lamentava o pouco conhecimento que se tinha da obra de Alberto Sampaio, foram publicados dois volumes com as suas obras principais, sob o título genérico de Estudos Históricos e Económicos ${ }^{4}$. O volume I abre com um elucidativo e pertinente prefácio daquele autor sobre Alberto Sampaio e a sua obra (p. V-XXIX). Em 1979 foi reeditada a dita obra, desta vez com prefácio de Maria José Trindade 5 .

Entretanto, foram devidamente assinaladas três datas marcantes relacionadas com o autor de As Póvoas Marítimas: o centenário e os 150 anos do seu nascimento, respectivamente em 1941 e 1991, e o centenário da sua morte, em 2008. Tratou-se de ocasiões propícias à realização de eventos evocativos que, além dos aspectos memorialísticos inerentes a tais iniciativas, permitiram aprofundar o estudo e a difusão da vida e obra de Alberto Sampaio.

Assim, em 1941 o referido centenário foi assinalado por meio de diversos eventos, entre os quais o descerramento de placas numa das ruas de Guimarães e na casa desta cidade onde nasceu e a colocação da primeira pedra do seu monumento, assim como a publicação, na Revista de Guimarães, de textos e de correspondência inédita de Alberto Sampaio ${ }^{6}$. Sob este ponto de vista,

marães, 1995, p. 373-374. Relativamente à mesma temática, no que respeita a Antero de Quental, ver Onésimo Teotónio de Almeida, «Antero e as Causas da Decadência dos Povos Peninsulares: entre Marx e Weber», Congresso Anteriano Internacional. Actas. 14-18. Outubro. 1991, Ponta Delgada, Universidade dos Açores, p. 33-43.

${ }^{3}$ José Amado Mendes, «Alberto Sampaio, precursor da história do presente», Boletim Cultural. Câmara Municipal de Vila Nova de Famalicão, III série, n. ${ }^{\circ}$ 3/4, 2007/2008, p. 415-426.

${ }^{4}$ Porto, Livraria Chardron, 1923.

${ }^{5}$ Vols. I e II, Lisboa, Editorial Veja, 1979.

${ }^{6}$ Revista de Guimarães, LI, n. ${ }^{\circ} 3$ (tiragem especial), 1941, p. 5-16. 
mais recentemente foi dado novo e relevante contributo, com a publicação da correspondência de e dirigida a Alberto Sampaio ${ }^{7}$.

No âmbito das comemorações dos 150 anos do nascimento do autor realizou-se, em Guimarães (nos dias 15, 16 e 17 de Novembro de 1991), o Congresso Histórico, cujas actas viriam a ser posteriormente publicadas, com as respectivas comunicações ${ }^{8}$. Pelo número de intervenientes e pelas temáticas focadas, pode dizer-se que se tratou de um momento alto de reflexão e aprofundamento dos estudos acerca da vida e obra do autor.

Por sua vez, em 2007-2008, realizaram-se diversas iniciativas, por ocasião do centenário da morte do autor de A Propriedade e Cultura do Minho, das quais se salientaram exposições ${ }^{9}$, publicações ${ }^{10}$ e o Congresso Comemorativo do Centenário de Alberto Sampaio (27-29 de Novembro de 2008), aguardando-se a publicação das respectivas actas. Ainda no âmbito do mesmo evento foi efectuada uma nova edição das Obras de Alberto Sampaio ${ }^{11}$. Mais recentemente (2012), novo e importante contributo foi dado para o conhecimento do autor e da sua obra, no âmbito de Guimarães Capital Europeia da Cultura, através da publicação da Fotobiografia. Alberto Sampaio. A Paixão das Origens, objecto desta recensão.

A obra, de Emília Nóvoa Faria e António Martins, está estruturada do seguinte modo: um prefácio, intitulado «Um caso especial», de Guilherme d'Oliveira Martins, seis capítulos, uma cronologia e bibliografia.

No prefácio, reitera-se o que tem sido sublinhado por vários investigadores, designadamente o facto de estarmos «perante o autêntico fundador da moderna história económica de Portugal» (p.14). Por outro lado, contextualiza-se a vida e a obra de Alberto Sampaio no seu tempo, o meio cultural e social em que viveu e a forma cívica e empenhada com que defendeu causas

${ }^{7}$ Emília Nóvoa Faria e António Martins (organização e notas), Correspondência, vol. I: Cartas a Alberto Sampaio, Porto, Ed. Campo das Letras, 2008; vol. II: Cartas de Alberto Sampaio, Vila Nova de Famalicão, Ed. Húmus, 2009.

${ }^{8}$ Actas do Congresso Histórico. 150 Anos do Nascimento de Alberto Sampaio, Guimarães, Câmara Municipal de Guimarães, 1995. Pouco depois foi publicada o trabalho de Barroso da Fonte, O Pensamento e a Obra de Alberto Sampaio, Guimarães, ed. de Autor, 1998.

${ }^{9}$ Entre outras recordam-se as exposições: Alberto Sampaio: Exposição Bibliográfica (Guimarães); Mostra Documental (Vila Nova de Famalicão); Os Frutos da Terra em Alberto Sampaio (Vila Nova de Famalicão); e Alberto Sampaio e o seu Tempo (Braga).

${ }^{10}$ Por exemplo: Alberto Sampaio. Exposição Bibliográfica, Guimarães, Museu Alberto Sampaio; Emília Nóvoa de Faria (Ilustração de Fedra Santos), Personagens com História. História de Alberto, Porto, Ed. Campo das Letras, 2007.

${ }^{11}$ Alberto Sampaio, Obras. Introdução de José Amado Mendes, Guimarães, Sociedade Martins Sarmento, 2008. 
nobres e princípios basilares da nossa história, remota e recente, e da trajectória política do país.

No capítulo I, sob o título "Primeiros Anos", focam-se e apresentam-se imagens relacionadas com as origens familiares de Alberto Sampaio, o seu nascimento, o tempo de Boamense (com interessantes fotografias da respectiva casa, em duplas páginas: 36-37 e, já no capítulo IV, 180-181) e o Colégio de Landim. Além das imagens do ambiente, das localidades e dos edifícios aos quais o autor esteve ligado nos primeiros anos de vida, em termos familiares, institucionais e educativos, reproduzem-se documentos alusivos.

O capítulo II é dedicado aos "Tempos de Coimbra". Os anos que Alberto Sampaio passou nesta cidade (1857-1863), para fazer o curso preparatório e frequentar o curso universitário de Direito, concluído no dia 29 de Maio de $1863^{12}$, foram marcantes na vida do autor. De facto, naquele período agitado e de efervescência da mocidade de então, liderada por Antero, além do estudo e da preparação académica consolidavam-se amizades, discutiam-se ideias, contestava-se e criticava-se duramente o status quo, de cuja crítica a polémica "Bom Senso e Bom Gosto" (1865) é o episódio mais conhecido, mas o respectivo contexto já vinha sendo preparado nos anos precedentes, tento Alberto e seu irmão José Sampaio sido protagonistas activos de muitas das manifestações de insatisfação desencadeadas no seio da academia.

A ilustração permite visualizar parte das instalações universitárias, fotografias de Antero de Quental e Alberto Sampaio (as quais escasseiam, devido à sua discrição e temperamento reservado), documentos e testemunhos diversos, referentes não só à vida académica como também à irrequietude dos estudantes, com destaque para os que faziam parte da Sociedade do Raio.

No capítulo III, sob a designação "Anos de inquietude" (finais dos anos de 1860 e década de 1870), abordam-se diversas facetas da actividade do autor, desde a sua passagem por Lisboa - experiência que não lhe agradou - até às viagens ao estrangeiro e chamamento da terra, à qual regressava com frequência. Ao mesmo tempo que ia cultivando as letras - submetendo à apreciação de Alexandre Herculano alguns dos seus poemas -, iniciava o seu percurso como vitivinicultor, procedendo a estudos e praticando no terreno, não só experimentando plantar novas castas como melhorando os processos de produção e preparação vinícola. Os documentos reproduzidos são bem esclarecedores desta nova vertente biográfica do autor, labor que viu consagrado logo

${ }^{12}$ Arquivo da Universidade de Coimbra, «Direito. Actos», 23, 1861-1865, fl. 192. 
em 1876, na Exposição Internacional de Filadélfia, onde o vinho da Quinta de Boamense foi galardoado com medalha de bronze (p. 116-117).

Foi ainda nos anos de 1870 que Alberto Sampaio exerceu uma actividade profissional, como guarda-livros do Banco de Guimarães (1873-1878) ${ }^{13}$. A competência e o empenho com que exerceu as referidas funções são testemunhadas pela carta que lhe dirige um dos membros da direcção do Banco, solicitando-lhe que ficasse mais algum tempo no seu cargo: «Os meus colegas pensam como eu, porque, tão bem como eu, conhecem a dificuldade que temos em encontrar quem o substitua, já não digo com todas as suas qualidades e habilitações, mas ao menos com a capacidade para ocupar o lugar» ${ }^{14}$. Alberto Sampaio esteve também ligado, como um dos fundadores, ao importante empreendimento termal de Caldas de Vizela, em 1873 (p.122-123).

Em 1878 Alberto Sampaio, acompanhado do seu amigo Antero de Quental, como "guia" ${ }^{15}$, deslocou-se à Exposição Universal de Paris, tendo aproveitado o ensejo para visitar igualmente museus e galerias da capital francesa que, como declarava, era o que mais lhe interessava (p. 136).

Nos anos de 1880-1890, encontra-se em pleno vigor e maturidade (capítulo IV), pelo que se dedica a um conjunto diversificado de tarefas, embora muito centradas em duas principais: investigação histórica e vitivinicultura. O essencial da sua obra foi produzido neste período e a meticulosidade, o rigor e empenho transparecem não apenas nos próprios trabalhos elaborados como na correspondência que manteve com os principais vultos do seu tempo, parte da qual visava precisamente aspectos relacionados com a investigação.

${ }^{13}$ Sobre a referida instituição bancária ver José Manuel Lopes Cordeiro, «Banco de Guimarães», Miguel Figueira de Faria e José Amado Mendes (coord.), Dicionário de História Empresarial Portuguesa. Séculos XIX e XX, volume I: Instituições Bancárias, Lisboa, Imprensa Nacional-Casa da Moeda, 2013, p. 175-176. Note-se, contudo, que o período em que Alberto Sampaio desempenhou as ditas funções foi mais longo (1873-1878) do que se indica no trabalho referido (1874-1876).

${ }^{14}$ Carta de Francisco Ribeiro Martins da Costa (de 11 de Setembro de 1877), in Emília Nóvoa Faria e António Martins (Org., introd. e notas), Correspondência, vol. I, p. 79.

${ }^{15}$ Antero de Quental tinha residido em Paris em 1866, para onde partira a fim de concretizar os seus ideais como operário tipógrafo, após ter sido aprendiz do ofício em Lisboa, na Imprensa Nacional. Contudo, a experiência não correu bem, pelo que, em finais de Dezembro daquele ano, escreveu a Alberto Sampaio, solicitando-lhe abrigo na sua Quinta de Boamense, durante um ano, mas recomendando-lhe que não informasse a família e os amigos do seu regresso prematuro, pois não se sentia bem com esse desfecho (Ana Maria Almeida Martins [Organização, introdução e notas], Obras Completas. Antero de Quental. Cartas I [1852]-1881, Lisboa, Editorial Comunicação, 1989, p. 85-87). 
$\mathrm{Na}$ verdade, correspondeu-se não só com os amigos mais dedicados, Antero de Quental, Oliveira Martins, Jaime de Magalhães Lima e Luís de Magalhães, como ainda com Martins Sarmento, José Leite de Vasconcelos, Camilo Castelo Branco, Bento Carqueja e vários outros. Foi também uma espécie de consultor e revisor de muitas das obras dos seus amigos, entre as quais o conhecido Projecto de Lei de Fomento Rural (Fotobiografia, p. 219) de Oliveira Martins (1887) que, como reconheceu o seu autor, muito ficou a dever a Alberto Sampaio.

Apesar da sua relutância em se envolver em iniciativas de carácter estritamente político, participou contudo, activamente, em eventos de índole científica, cultural e cívica, como a colaboração em diversas publicações periódicas, a fundação da sociedade Martins Sarmento, em 1881 (p. 196-201) e a importante Exposição Industrial de Guimarães, realizada em 1884 (p.204-206), da qual foi o principal promotor e dinamizador - foi mesmo considerado "a alma da exposição" - e sobre a qual escreveu textos importantes, tendo sido ainda o responsável pelo Catálogo ${ }^{16}$. Esta não só foi um sucesso - pois em pouco mais de um mês (15 de Junho a 26 de Julho de 1884) acolheu mais de 10000 visitantes -, com permitiu alcançar o seu principal objectivo, que era o da criação de uma Escola Industrial em Guimarães, o que se concretizou logo em finais desse mesmo $\mathrm{ano}^{17}$. As diversas imagens apresentadas sobre o evento, o local, a documentação e as publicações são bem elucidativas da relevância alcançada pelo evento.

Nos capítulos V e VI, intitulados "A paixão das origens" e os "Últimos anos", dá-se conta da evolução dos trabalhos de investigação de Alberto Sampaio e da boa receptividade que aqueles iam alcançando junto de especialistas e de interessados pela pesquisa histórica. São reproduzidos artigos de notícias que entretanto iam saindo sobre as obras do autor, assim como outros documentos, textos originais e provas tipográficas. Apresentam-se imagens e documentos interessantes relativos aos seguintes trabalhos: A Propriedade e a Cultura do Minho, O Norte Marítimo, As Vila do Norte de Portugal e As Provas Marítimas do Norte de Portugal.

Nos últimos anos de vida, Alberto Sampaio prosseguiu com as suas investigações até quase às vésperas do seu óbito (1908), embora com frequentes

${ }^{16}$ Relatório da Exposição Industrial de Guimarães em 1884, Porto, Tipografia de António José da Silva Teixeira, 1884, p. 140.

${ }^{17}$ A Escola Industrial Francisco de Holanda de Guimarães foi fundada em 3 de Dezembro de 1884, enquanto a Escola de Desenho Industrial havia sido criada em 22 de Março do mesmo ano (Joaquim Ferreira Gomes, «Escolas Industriais e Comerciais criadas no século XIX», Revista Portuguesa de Pedagogia, Ano XII, 1978, p. 105). 
expressões de tristeza e lamentos pela ausência dos familiares a amigos mais íntimos que, entretanto, vira partir, desde Antero de Quental (1891), Oliveira Martins (1894), Martins Sarmento (1899), seu irmão, José Sampaio (1899) e Eça de Queirós (1900).

Nas últimas páginas apresentam-se algumas fotografias do autor, bem como documentação comprovativa do apreço que os seus trabalhos mereciam junto de investigadores credenciados, bem como a sua continuada actividade como investigador, deslocando-se frequentemente ao Porto, para aí completar as suas pesquisas.

A cronologia, apresentada no final da obra (páginas não numeradas), constitui um bom instrumento de trabalho, pois trata-se de uma resenha sucinta do Curriculum Vitae do autor.

Numa breve apreciação de conjunto da presente obra ressalta, por um lado, o critério abrangente seguido, o qual permitiu documentar e ilustrar as múltiplas facetas da vida e obra de Alberto Sampaio, desde os seus ascendentes familiares à formação académica, da investigação às viagens, da vasta troca de correspondência à profunda amizade que o ligava aos seus amigos mais íntimos. Parte da documentação e das imagens reproduzidas é inédita, o que nos permite ficar a conhecer melhor este grande vulto da cultura e da historiografia portuguesa.

O trabalho tem boa apresentação e foi cuidadosamente revisto, pelo que apenas se detectam pequenos lapsos de pormenor, a corrigir em eventual futura reedição. Assim, na página 270, refere-se o «concelho de Nela» em vez do concelho de Nelas; nas páginas 88 e 91 indicam-se datas diferentes para a formatura do autor: 29 de Maio e Dezembro de 1863. Como vimos anteriormente, a data correcta é a primeira. Por último, a Exposição de Paris de 1878 aparece designada como "universal", em dois locais (p. 134 e cronologia) e como "internacional", noutro (p. 136). Tratou-se, de facto, de uma Exposição Universal ${ }^{18}$.

Obviamente que o que se acaba de referir não afecta, minimamente, o mérito da presente obra que nos permite apreender, com maior detalhe, muitos dos eventos relacionados com Alberto Sampaio, «um dos grandes mestres da historiografia portuguesa» ${ }^{19}$.

\section{José Amado Mendes}

Universidade de Coimbra

Universidade Autónoma de Lisboa

${ }^{18}$ Las Exposiciones Universales. Catedra de Urbanistica I. Curso 1984/85. E T. S.A., Madrid, Colegio Oficial de Arquitectos de Madrid, 1986, p. 80-81.

${ }_{19}$ Jorge Borges de Macedo, «Alberto Sampaio no pensamento histórico português», Actas do Congresso Histórico 150 anos do nascimento de Alberto Sampaio, cit., p. 414. 